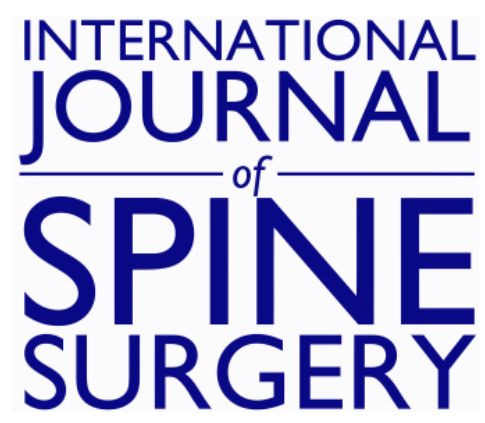

\title{
Comparative Analysis of Unilateral versus Bilateral Instrumentation in TLIF for Lumbar Degenerative Disorder: Single Center Large Series
}

Vigneshwara Badikillaya, Keyur K. Akbari, Pramod Sudarshan, Hardik Suthar, Muralidharan Venkatesan and Sajan K. Hegde

Int J Spine Surg published online 22 September 2021

http://ijssurgery.com/content/early/2021/09/20/8121

This information is current as of April 26, 2023.

Email Alerts Receive free email-alerts when new articles cite this article. Sign up at: http://ijssurgery.com/alerts 


\title{
Comparative Analysis of Unilateral versus Bilateral Instrumentation in TLIF for Lumbar Degenerative Disorder: Single Center Large Series
}

\author{
VIGNESHWARA BADIKILLAYA, MS (ORTHO), ${ }^{1}$ KEYUR K. AKBARI, MS (ORTHO), ${ }^{1}$ PRAMOD \\ SUDARSHAN, MS (ORTHO), ${ }^{2}$ HARDIK SUTHAR, MS (ORTHO), ${ }^{3}$ MURALIDHARAN VENKATESAN, \\ MRCS, MBBS, MCH (ORTHO), FRCS (ORTHO), ${ }^{1}$ SAJAN K. HEGDE, MS (ORTHO) ${ }^{1}$ \\ ${ }^{I}$ Apollo Hospital, Chennai, India, ${ }^{2}$ Aster MIMS Hospital, Kozhikode, India, ${ }^{3}$ BJ Medical College, Ahmedabad, India
}

\begin{abstract}
Background: Transforaminal lumbar interbody fusion (TLIF) with bilateral pedicle screw instrumentation is a well-accepted technique in lumbar degenerative disc disorder. Unilateral instrumentation in TLIF has been reported in the literature. This study aims to compare the clinical and radiological outcomes of unilateral and bilateral instrumented TLIF in a selected series of patients.

Methods: We retrospectively analyzed patients operated with unilateral pedicle screw fixation in TLIF (UPSF TLIF) or with bilateral pedicle screw fixation in TLIF (BPSF TLIF) with a minimum of 2 years of follow-up. Patients were evaluated at regular intervals for functional and radiological outcomes. Functional outcome was assessed using the Oswestry disability index (ODI) and visual analog score (VAS) preoperatively and at 6 months, 1 year, and 2 years after surgery. Fusion rates were assessed using Bridwell interbody fusion grading.

Results: Our study shows that there was a significant improvement in VAS and ODI in both groups at 2 years follow-up, and there was no significant difference in improvements between the groups. The complication rates between the groups were similar. The fusion rate in UPSF TLIF was $97.3 \%$ and was $98.34 \%$ in BPSF TLIF; this was not statistically significant between groups. There is a significant difference in terms of blood loss, duration of surgery, and average duration of hospital stay between the groups $(P<.001)$, favoring UPSF TLIF.

Conclusions: Unilateral pedicle screw fixation in open TLIF is comparable with bilateral pedicle screw fixation in terms of patient-reported clinical outcomes, fusion rates, and complication rates with the additional benefits of less operative time, less blood loss, shorter hospitalization, and less cost in selective cases.
\end{abstract}

Level of Evidence: 4.

Lumbar Spine

Keywords: unilateral pedicle screw fixation, lumbar fusion, interbody fusion, transforaminal lumbar interbody fusion

\section{INTRODUCTION}

The transforaminal lumbar interbody fusion (TLIF) technique was described by Harms and Jeszenszky in 1998 for symptomatic lumbar degenerative disc disorder. ${ }^{1}$ Since then, TLIF has become a well-accepted technique to perform interbody fusion with less neural retraction through a single posterior approach..$^{2-9}$ Interbody cage arthrodesis of the lumbar spine in combination with pedicle screw instrumentation provides immediate structural support and a high fusion rate. ${ }^{10-13}$

In the TLIF procedure, bilateral pedicle screw/ rod fixation has been shown to increase fusion rates and is now standard with the procedure. ${ }^{14-19}$ However, bilateral pedicle instrumentation warrants extensive paravertebral muscle dissection and retraction for the standard open TLIF procedure. ${ }^{2-}$ 20,21 The significant iatrogenic paraspinal muscle and soft tissue injury that occurs during the bilateral pedicle screw instrumentation surgical approach is associated with longer operative time, greater blood loss, increased postoperative pain, lengthened recovery time, and use of more spinal instrumentation, all correlated to an increased risk of complications in adult spinal surgery. ${ }^{22-24}$

Unilateral pedicle screw instrumentation in TLIF has been described in the literature and may be more desirable because it is less invasive and entails less operative time, less blood loss, and less destruction of posterior structures. In addition, bilateral fixation may increase stress at adjacent intervertebral levels 
due to increased stiffness, which can ultimately lead to adjacent segment degeneration. ${ }^{25}$

In this study, we hypothesized that the open TLIF with unilateral pedicle screw instrumentation is clinically equivalent to bilateral pedicle screw constructs. This is the largest clinical comparative series of open TLIF with unilateral versus bilateral instrumentation.

\section{METHODS}

After obtaining our institutional review board approval, we performed a retrospective review of our prospective database for patients who had undergone a single-level open TLIF procedure with either unilateral pedicle screw fixation (UPSF) or bilateral pedicle screw fixation (BPSF) instrumentation in a selected group of patients from June 2014 to June 2017 with a minimum 2 years of follow-up. Indications for inclusion were all skeletally mature patients with predominant leg radiculopathy or claudication secondary to degenerative disc disorder, grade 1 degenerative spondylolisthesis, or recurrent disc protrusion and failed conservative treatment for a minimum of 6 weeks. We excluded patients with bilateral radiculopathy, grade 2 or above degenerative spondylolisthesis, lytic spondylolisthesis, degenerative scoliosis, active infection, osteopenia (dual-energy x-ray absorptimetry $T$ score $<-1.5$ ), and a body mass index of $>30$. Preoperative standard standing anteroposterior and lateral radiographs of the lumbosacral spine were done to assess the instability by the radiographic criteria of Myerdings. ${ }^{26}$ Magnetic resonance imaging of the spine was done routinely to delineate the intraspinal pathoanatomy.

Patients with BPSF TLIF were compared with those with a UPSF construct. This study included 112 cases of UPSF TLIF and 121 cases of age- and sex-matched BPSF TLIF who fulfilled the inclusion criteria.

All patients were operated on by the senior author. Interbody cage material placed in the surgeries was polyetheretherketone, and a single pedicle screw system was used for all cases.

Patient demographics, diagnosis, duration of symptoms, levels of fusion, operating time, intraoperative estimated blood loss, risk factors for fusion, and length of hospital stay were all collated. Preoperative and postoperative pain status was assessed by self-evaluated visual analog score $(\mathrm{VAS})^{27,28}$ and disability by Oswestry disability index (ODI). ${ }^{29,30}$ After discharge from the hospital, the patients followed up with the surgeon at 2 and 6 weeks, 6 months, 1 year, and 2 years. Plain lumbar spine radiographs were obtained at each follow-up to assess fusion and monitor complications. The radiological outcome of interbody fusion was assessed with the Bridwell grading system. ${ }^{31}$ Computed tomography findings were assessed 2 years after surgery for patients with a doubtful union in plain radiographs.

Our primary outcome measures of pain and disability were assessed with patient-reported outcome measures VAS and ODI. Secondary outcome measures included length of surgery, intraoperative estimated blood loss, length of stay, perioperative complication, and fusion rate.

\section{Statistical Analysis}

All the analyses were performed using Stata 14.2 software. We used two sample $t$ tests with equal variances to compare the means between the groups. A $P$ value of $\leq .05$ was considered to indicate a statistically significant difference between the groups.

\section{Surgery Technique}

\section{BPSF TLIF}

After induction of anesthesia, the patient was positioned prone in a Jackson table. The operative field was painted and draped. Midline posterior incision over the offending disc level and the paraspinal muscles were subperiosteally elevated to expose posterior elements of the spine to the base of the transverse process bilaterally. The facet joint above and at the offending disc level was exposed. Pedicle screws were inserted in the above and below vertebral body of the offending disc using free-hand technique on both sides. Unilateral partial medial facetectomy, laminectomy, and decompression were performed on the symptomatic side, and the disc space on the ispilateral symptomatic side was approached after pedicle screw-based distraction. The disc was resected in standard fashion using rongeurs, shavers, and curettes, and the anterior part of the disc space was packed with autologous graft prepared from facetectomy and laminotomy. An adequate-sized single polyetheretherketone cage filled with autologous bone chips was inserted into the posterior part of the prepared disc space through the symptomatic side. After the placement 


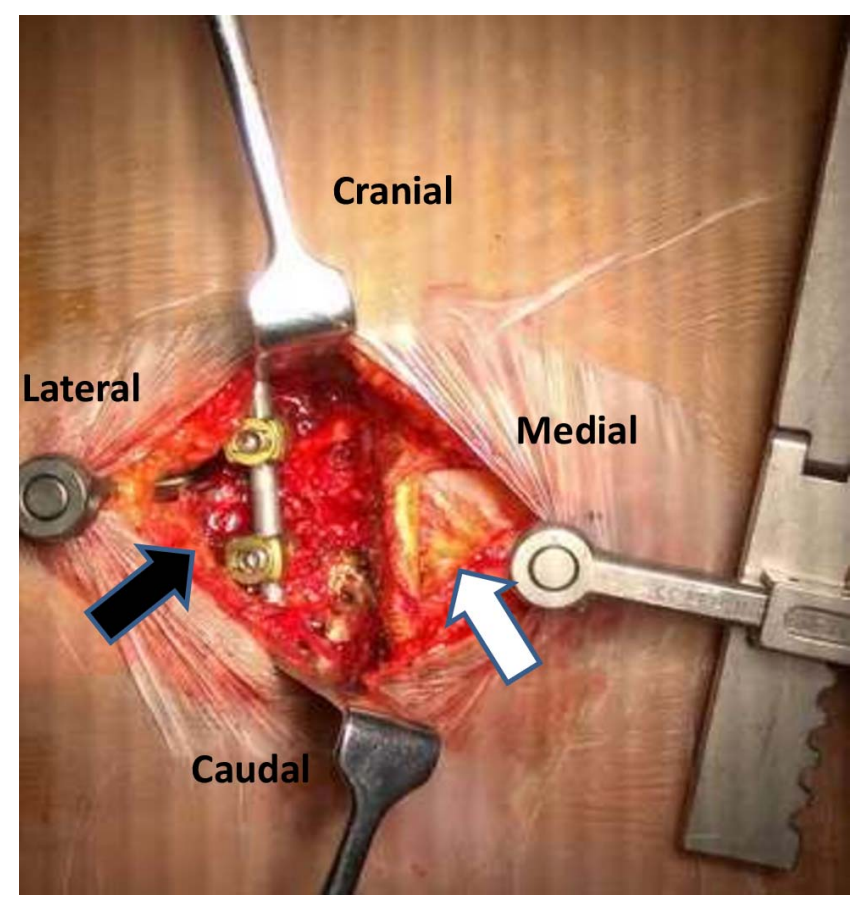

Figure 1. Image showing the unilateral exposure and instrumentation after posterior midline skin incision (black arrow) with intact contralateral paraspinal musculature (white arrow).

of the cage, pedicle screw-based compression was achieved, and final cage position was confirmed with fluoroscopy. The wound was copiously irrigated, drainage catheters were placed, and the wounds were closed in layers.

\section{UPSF TLIF}

After positioning and draping as mentioned above, the midline skin incision was taken over the offending level. Paraspinal muscles were elevated subperiosteally only on the symptomatic side. Both superior and inferior pedicle screws were placed unilaterally through free-hand technique. Ipsilateral partial medial facetectomy, laminectomy, and decompression were done, and disc space on the ipsilateral symptomatic side was approached after pedicle screw-based distraction (Figure 1). The disc was resected in standard fashion, and the anterior part of the disc space was packed with local autologous graft. An adequate-sized single polyetheretherketone cage filled with autologous bone chips was inserted into the posterior part of the prepared disc space. After the placement of the cage, pedicle screw-based compression was achieved, and the final cage position was confirmed with fluoroscopy. The wound was irrigated and closed in layers without placement of a drainage catheter.
Table 1. Patient/operative characteristics.

\begin{tabular}{lccc}
\hline Parameter & UPSF TLIF & BPSF TLIF & $P$ Value \\
\hline$N$ & 112 & 121 & \\
Age, mean, y & $53.6(26-70)$ & $58.3(28-80)$ & $>.05$ \\
Sex, M/F & $64 / 48$ & $65 / 56$ & .9 \\
Diagnosis for operation & & & \\
$\quad$ Recurrent disc herniation & 5 & 8 & \\
$\quad$ Lumbar canal stenosis & 48 & 54 & \\
$\quad$ Grade 1 spodylolysthesis & 33 & 40 & \\
$\quad$ Degenerative disc disease & 26 & 19 & \\
Level & & & \\
$\quad$ L2-3 & 1 & 0 & \\
$\quad$ L3-4 & 14 & 16 & \\
$\quad$ L4-5 & 61 & 64 & \\
L5-S1 & 36 & 41 & \\
Preoperative duration & 5.4 & 6.2 & \\
$\quad$ of symptoms, mo & & & \\
Follow-up, mean (range), mo & $26.2(24-48)$ & $26.6(24-48)$ & \\
Preoperative back VAS & 6.2 & 6.7 & \\
Preoperative leg VAS & 7.1 & 7.5 & \\
Preoperative ODI & 56.9 & 58.5 & \\
\hline
\end{tabular}

Abbreviations: BPSF TLIF, bilateral pedicle screw fixation in transforaminal lumbar interbody fusion; F, female; M, male; ODI, Oswestry disability index; UPSF TLFI, unilateral pedicle screw fixation in transforaminal lumbar interbody fusion; VAS, visual analog score.

Generous autografting of the fusion bed with morselized bone harvested locally from partial facetectomy and laminectomy was done as routine. No allograft or synthetic bone substitutes were used in any cases. No additional posterolateral fusion was performed in any case.

\section{RESULTS}

Tables 1 and 2 demonstrates the patient characteristics of the study groups. There was no difference between the groups in terms of age, gender, diagnosis, duration of symptoms, or risk factors for fusion (eg, body mass index, diabetes, and smoking). L4/5 was the most common operating level followed by L5/S1 in both groups. The mean follow-up was 26.4 months (24-36 months). Both groups demonstrated similar preoperative pain and disability index scores. There was no statistically significant difference in preoperative ODI and VAS for back and leg pain between the groups $(P>.05)$.

Significant differences were found in mean operating time (75.18 minutes in the UPSF group

Table 2. Comparison of risk factors for fusion between the two groups.

\begin{tabular}{lccc}
\hline Risk Factors for Fusion & $\begin{array}{c}\text { UPSF TLIF } \\
\text { Group }\end{array}$ & $\begin{array}{c}\text { BPSF TLIF } \\
\text { Group }\end{array}$ & $\boldsymbol{P}$ Value \\
\hline BMI, mean (SD) & $23.6(2.8)$ & $23.9(3)$ & $>.05$ \\
Diabetes, $n$ (\%) & $36(32.1)$ & $39(32.2)$ & $>.05$ \\
Chronic smoking, $n(\%)$ & $22(19.6)$ & $26(21.4)$ & $>.05$ \\
\hline
\end{tabular}

Abbreviations: BMI, body mass index; BPSF TLIF, bilateral pedicle screw fixation in transforaminal lumbar interbody fusion; UPSF TLFI, unilateral pedicle screw fixation in transforaminal lumbar interbody fusion. 
Table 3. Comparison of perioperative parameters between groups.

\begin{tabular}{lccc}
\hline Parameters & UPSF TLIF & BPSF TLIF & $\boldsymbol{P}$ Value \\
\hline Operative time, min & 75.18 & 93.38 & $<.0001$ \\
Estimated blood loss, mL & 76.9 & 122.3 & $<.0001$ \\
Length of hospital stay, days & 1.7 & 2.8 & $<.0001$
\end{tabular}

Abbreviations: BPSF TLIF, bilateral pedicle screw fixation in transforaminal lumbar interbody fusion; UPSF TLFI, unilateral pedicle screw fixation in transforaminal lumbar interbody fusion.

versus 93.38 minutes in the BPSF group) between the 2 groups $(P<.0001)$. Intraoperative estimated blood loss was less in the UPSF group $(76.9 \mathrm{~mL})$ than in the BPSF group $(122.3 \mathrm{~mL})$, and this was statistically significant $(P<.0001)$. Furthermore, patients in the UPSF group had a shorter hospital stay than patients in the BPSF group (1.7 days versus 2.8 days, $P<.0001$; Table 3 ).

The VAS score for back and leg pain and the ODI showed significant improvement in both groups postoperatively $(P<.05)$. Improvements in VAS and ODI noted at 6 months postoperatively were maintained at 2 years follow-up in both groups $(P>.05$; Table 4). However, there was no significant difference noted in the improvement of back pain VAS, leg pain VAS, and ODI between the groups at 6 months or 2 years follow-up after surgery $(P>.05$; Table 4$)$. Radiological evidence of fusion was noted in $97.3 \%$ and $98.4 \%$ of patients in the UPSF group (Figure 2) and BPSF group, respectively, and the difference in fusion rate was
Table 4. Comparison of functional and radiological outcome between groups.

\begin{tabular}{lccc}
\hline & UPSF TLIF & BPSF TLIF & $\boldsymbol{P}$ Value \\
\hline Postoperative back VAS & 6.2 & 6.7 & $>.05$ \\
At 6 mo & 3.2 & 3.4 & $>.05$ \\
At 2 y & 2.2 & 2.1 & .461 \\
Postoperative leg VAS & 7.1 & 7.5 & $>.05$ \\
At 6 mo & 0.8 & 0.9 & $>.05$ \\
At 2 y & 0.7 & 0.6 & $>.05$ \\
Postoperative ODI & 56.9 & 58.5 & $>.05$ \\
At 6 mo & 25.8 & 27.2 & $>.05$ \\
At 2 y & 16.9 & 16.6 & .676 \\
Fusion at final follow-up & 97.3 & 98.4 & $>.05$ \\
\hline
\end{tabular}

Abbreviations: BPSF TLIF, bilateral pedicle screw fixation in transforaminal lumbar interbody fusion; ODI, Oswestry disability index; UPSF TLFI, unilateral pedicle screw fixation in transforaminal lumbar interbody fusion; VAS, visual analog score.

not statistically significant between the groups $(P>$ $.05)$

Complication rates between the UPSF and BPSF groups were similar $(6.25 \%$ for UPSF versus $6.6 \%$ for BPSF, $P>.05$; Table 5). Overall, there were three cases of superficial wound infection with one case in UPSF and 2 cases in the BPSF group, which responded to oral antimicrobial therapy. There were three new cases of postoperative iatrogenic foot drop in this series $(1.2 \%)$. One case of foot drop in UPSF was due to pedicle screw malposition, and this failed to improve despite repositioning. Two cases of foot drop in BPSF were unexplainable (indirect neural injury) with full recovery in one case at 3 weeks postoperation, and the other case had a

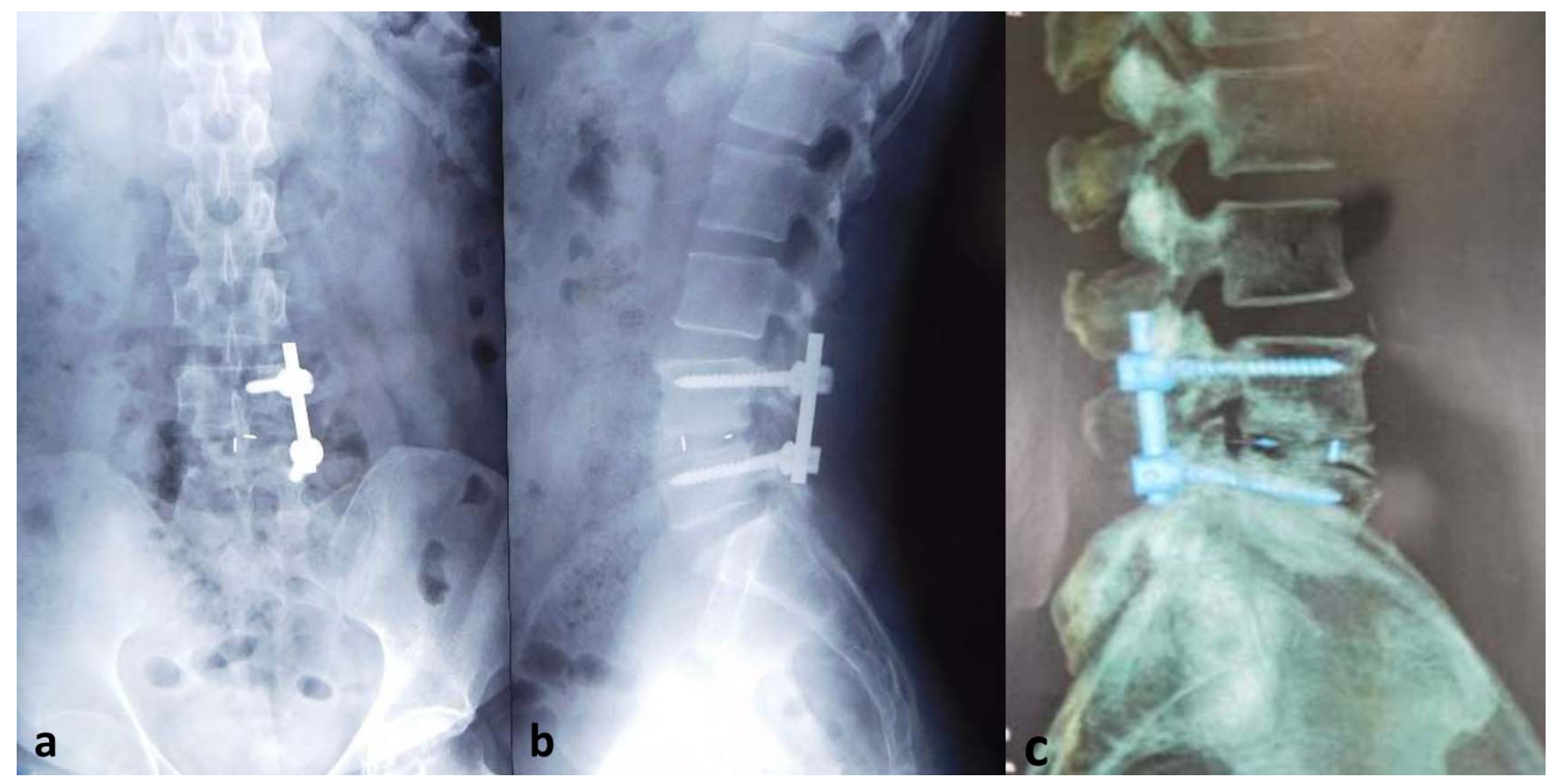

Figure 2. (a, b) Illustrative case of unilateral instrumentation transforaminal lumbar interbody fusion (TLIF) showing 2-year postoperative plain anterior-posterior (a) and lateral (b) radiographs of L4-L5 unilateral instrumentation TLIF. (c) Sagittal section computed tomography of the same patient confirming bony fusion. 
Table 5. Comparison of complications between the groups. ${ }^{\text {a }}$

\begin{tabular}{lcc}
\hline & UPSF TLIF, $\boldsymbol{n}(\mathbf{\%})$ & BPSF TLIF, $\boldsymbol{n}(\%)$ \\
\hline Superficial infection & $1(0.89)$ & $2(1.6)$ \\
Foot drop & $1(0.89)$ & $2(1.6)$ \\
Cage migration & $2(1.7)$ & $2(1.6)$ \\
Pseudarthrosis & $3(2.6)$ & $2(1.6)$ \\
Total & $7(6.25)$ & $8(6.6)$ \\
\hline
\end{tabular}

Abbreviations: BPSF TLIF, bilateral pedicle screw fixation in transforaminal lumbar interbody fusion; UPSF TLFI, unilateral pedicle screw fixation in transforaminal lumbar interbody fusion.

${ }^{\mathrm{a}}$ There is no significant complications between the two groups $(P>0.05)$.

persistent weakness. Also, 4 cases of posterior cage migration into the spinal canal with two in each group were documented between 6 weeks and 3 months. All four cases remained asymptomatic and went on to have solid arthrodesis. The pseudarthrosis rate in the UPSF group was higher than in the BPSF group (2.6\% versus $1.6 \%)$, but this was not statistically significant $(P>.05)$.

The direct total hospital cost at our institution was $15 \%$ less for UPSF TLIF than for the BPSF construct. The implant cost alone for the BPSF TLIF was $35.5 \%$ greater than unilateral instrumentation.

\section{DISCUSSION}

Biomechanical studies have demonstrated the superiority of bilateral pedicle screws compared with unilateral pedicle screw constructs in open and minimally invasive surgical TLIF. ${ }^{32-36}$ Our study is the largest series to date comparing UPSF with BPSF in open TLIF in a selected series of patients. Our study also reported no significant difference in radiological fusion rate and complication rate between the groups (Table 6).

The inherent advantages of unilateral instrumentation include a less invasive approach with avoidance of soft tissue disruption on the contralateral side, reduced operation time, less blood loss, and lower implant costs. ${ }^{37-46}$ In our series, we document less intraoperative blood loss and operating time in the unilateral cohort than in the bilateral instrumentation group $(P<.0001)$. The present study reports significantly shorter hospital stay in the unilateral instrumented TLIF group than in the bilateral instrumentation group $(P<.0001)$. The cost of bilateral fixation is greater than unilateral fixation due to the greater instrumentation requirements of the former. We also found that those undergoing BPSF had longer operative time and greater blood loss, which further increases the direct and indirect costs of the bilateral instrumentation construct. At our institution, we found that the total hospital cost was $15 \%$ less for UPSF TLIF than for the BPSF construct. Globally, every health care system is struggling with rising costs and is working toward cost efficiency measures for sustainable health systems. Our largest comparative series supports that unilateral instrumentation is as good as bilateral instrumentation for select patients needing single-level TLIF. Less instrumentation without compromising the outcome is beneficial to both patients and service providers. Unilateral instrumentation means less surgical morbidity, less blood loss, less postoperative pain, and early recovery to patients. Less instrumentation is cost efficacious for service providers through low implant cost (direct saving) and indirect cost savings through reduced operation time and shorter hospital stay.

Some studies suggest that unilateral instrumentation may result in nonunion, metal failure, or cage migration due to the decreased strength or inherent asymmetry of this system. ${ }^{32,33,39}$ Goel et al showed that unilateral constructs were consistently less rigid than bilateral constructs in an in vivo animal model. ${ }^{32}$ By contrast, Slucky et al showed no difference in flexion/extension, lateral bending, or axial rotation when comparing BPSF constructs with UPSF constructs in human cadaver TLIF

Table 6. Comparison of our study with previous published literature.

\begin{tabular}{|c|c|c|c|c|c|c|c|c|c|}
\hline Study & $\begin{array}{l}\text { No. of } \\
\text { Patients, } \\
\text { Uni:Bi }\end{array}$ & $\begin{array}{l}\text { Age, y, } \\
\text { Uni:Bi }\end{array}$ & $\begin{array}{l}\text { Follow-up, } \\
\text { mo, Uni:Bi }\end{array}$ & $\begin{array}{l}\text { Most Common } \\
\text { Indication for } \\
\text { Surgery }\end{array}$ & $\begin{array}{c}\text { Fused } \\
\text { Segments }\end{array}$ & $\begin{array}{l}\text { Number } \\
\text { of Levels } \\
\text { Operated }\end{array}$ & $\begin{array}{l}\text { Type of } \\
\text { Surgery }\end{array}$ & $\begin{array}{c}\text { Mean ODI at } \\
\text { Final Follow-up, } \\
\text { Uni:Bi }\end{array}$ & $\begin{array}{c}\text { VAS (Leg Pain) at } \\
\text { Final Follow-up, } \\
\text { Uni:Bi }\end{array}$ \\
\hline Feng et al $2011^{38}$ & $20: 20$ & $53.8: 53.2$ & $3: 3$ & LSS & L3-S1 & 1 level & Open & 5.2:not estimable & \\
\hline Aoki et al $2012^{39}$ & $25: 25$ & $66.2: 65.6$ & $31.0: 31.2$ & LS grade 1,2 & L3-S1 & 1 level & Open & $\ldots$ & $3.7: 1.3$ \\
\hline Xie et al $2012^{40}$ & $56: 52$ & $56.2: 55.0$ & $>36$ & LSS & L3-S1 & $1 / 2$ level & Open & $\ldots$ & $\ldots$ \\
\hline Xue et al $2012^{41}$ & $37: 43$ & $57.1: 58.2$ & $25.3: 25.3$ & LSS & L3-S1 & $1 / 2$ level & Open & $15.4: 15.8$ & $\cdots$ \\
\hline Dahdaleh et al $2013^{42}$ & $16: 20$ & $62.2: 57.3$ & $11.4: 12.4$ & LS grade 1,2 & L3-S1 & 1 level & MIS & $22.7: 17.9$ & $2.6: 2.1$ \\
\hline Choi et al $2013^{43}$ & $26: 28$ & $53.6: 56.2$ & $27.5: 28.9$ & LSS & L3-S1 & 1 level & MIS & $6.6: 9.5$ & $1.7: 1.8$ \\
\hline Zhang et al $2013^{44}$ & $33: 35$ & $59.4: 55.7$ & $25.6: 25.6$ & LSS & L3-S1 & 2 level & Open & $18.8: 17.9$ & $1.9: 2$ \\
\hline Our study & $112: 121$ & $53.6: 58.3$ & $24: 24$ & LSS & L2-S1 & 1 level & Open & $16.9: 16.6$ & $2.2: 2.1$ \\
\hline
\end{tabular}

Abbreviation: LS, lumbar spondylolisthesis; LSS, lumbar spinal stenosis; MIS, minimally invasive surgery; Uni:Bi, unilateral:bilateral. 
specimens. ${ }^{33}$ Suk et al, ${ }^{37}$ Xue et al, ${ }^{41}$ and Dahdaleh et $\mathrm{al}^{42}$ in their small series comparative clinical studies reported no significant difference in fusion rate, cage migration, metalwork failure, and complication rate between unilateral instrumentation TLIF and bilateral instrumentation TLIF. These findings are confirmed in this large series, and our results demonstrate no significant difference in cage migration, pseudarthrosis, metalwork failure, or reoperation rate between the UPSF and BPSF groups.

In our series, there was no significant difference in the improvement in mean ODI and VAS between the UPSF and BPSF groups at any time point in the follow-up. The improvement in ODI and VAS was sustained after 6 months up to the latest follow-up in both groups. These findings are consistent with other small series studies. ${ }^{37-44}$

In our study, we observed a high fusion rate compared with other similar series in the literature. The documented fusion rate in other series ranges from $84.6 \%$ to $93.8 \%$ and from $94.3 \%$ to $96.3 \%$ in unilateral and bilateral instrumented TLIF respectively. We report a fusion rate of $97.3 \%$ in the unilateral and $98.4 \%$ in the bilateral instrumentation group. The high fusion rate observed in our study could be attributed to the traditional open approach with adequate access to disc space, meticulous disc space preparation, and adequate autologous bone grafting of the fusion bed.

Posterior cage migration is a recognized complication when an interbody cage is used for lumbar spine fusion, with the reported prevalence of $1.17 \%$ to $14.7 \%$ after TLIF or posterior lumbar interbody fusion. ${ }^{47-49}$ Undersizing of the cage, UPSF, bullettype cages, pear-shaped discs, surgeon experience, high preoperative disc height, and posterior position of the cage all have been reported as risk factors for posterior cage migration following TLIF or posterior lumbar interbody fusion. ${ }^{47-50}$ In our series, the overall posterior cage migration was $1.7 \%$ with no difference between unilateral and bilateral instrumented TLIF. All four cases were asymptomatic and went on to fusion in situ without compromising the patient clinical outcome. In our practice, there was no higher cage migration rate in unilateral instrumentation than in bilateral instrumentation, and it contradicts the previous documentation of unilateral instrumentation being a risk factor for posterior cage migration.
A recent systematic review and meta-analysis on the subject reported equivalency between unilateral and bilateral fixation when performed in adult patients who do not have significant unstable lumbar conditions. ${ }^{51}$

The present study has several strengths. These include a prospective database review, the largest number of patients in each group, specifically comparing open TLIF approach with either BPSF or UPSF, single-surgeon series standardizing the surgical technique, single pedicle screw system and intervertebral cage system, and the use of validated patient-reported outcome measures. The study also has unique selection criteria defining the target patient group that would benefit from unilateral instrumented TLIF for symptomatic lumbar degenerative disc disorder. This is the first and largest comparative study, which limits the confounding factors of other studies, validating the outcome that unilateral instrumentation in TLIF is safe and efficacious compared with traditional BPSF. The shortcoming of this study is that the surgery (either UPSF TLIF or BPSF TLIF) was offered to only a select group of patients as mentioned in the indications. However, the aim of the study is to highlight comprehensive criteria to select patients for unilateral fixation in TLIF. The other limitation is that we have not evaluated the influence of spinopelvic parameters on the outcome after single-level short spinal fusion.

\section{CONCLUSIONS}

UPSF in TLIF is comparable with BPSF in terms of patient-reported clinical outcomes, fusion rates, and complication rates with the additional benefits of less operative time, less blood loss, shorter hospitalization time, and less cost in selected cases of lumbar degenerative disc disorder.

\section{REFERENCES}

1. Harms JG, Jeszenszky D. Die posteriore, lumbale, interkorporelle fusion in unilateraler transforaminaler technik. Oper Orthop Traumatol. 1998;10(2):90-102. doi:10.1007/ s00064-006-0112-7

2. Potter BK, Freedman BA, Verwiebe EG, Hall JM, Polly DW Jr, Kuklo TR. Transforaminal lumbar interbody fusion: clinical and radiographic results and complications in 100 consecutive patients. J Spinal Disord Tech. 2005;18(4):337-346. doi:10.1097/01.bsd.0000166642.69189.45

3. Salehi SA, Tawk R, Ganju A, LaMarca F, Liu JC, Ondra SL. Transforaminal lumbar interbody fusion: surgical technique and results in 24 patients. Neurosurgery. 2004 
Feb;54(2):368-374; discussion 374. doi: 10.1227/01.neu. 0000103493.25162 .18 .

4. Goldstein CL, Phillips FM, Rampersaud YR. Comparative effectiveness and economic evaluations of open versus minimally invasive posterior or transforaminal lumbar interbody fusion: a systematic review. Spine (Phila Pa 1976). 2016;41(Suppl 8):S74-S89. doi:10.1097/BRS.0000000000001462

5. Dhall SS, Wang MY, Mummaneni PV. Clinical and radiographic comparison of mini-open transforaminal lumbar interbody fusion with open transforaminal lumbar interbody fusion in 42 patients with long-term follow-up. J Neurosurg Spine. 2008;9(6):560-565. doi:10.3171/SPI.2008.9.08142

6. Seng C, Siddiqui MA, Wong KP, et al. Five-year outcomes of minimally invasive versus open transforaminal lumbar interbody fusion: a matched-pair comparison study. Spine (Phila Pa 1976). 2013;38(23):2049-2055. doi:10.1097/ BRS.0b013e3182a8212d

7. Brodano GB, Martikos K, Lolli F, et al. Transforaminal lumbar interbody fusion in degenerative disk disease and spondylolisthesis grade I: minimally invasive versus open surgery. J Spinal Disord Tech. 2015;28(10):E559-E564. doi:10. 1097/BSD.0000000000000034

8. Lee KH, Yue WM, Yeo W, Soeharno H, Tan SB. Clinical and radiological outcomes of open versus minimally invasive transforaminal lumbar interbody fusion. Eur Spine $J$. 2012;21(11):2265-2270. doi:10.1007/s00586-012-2281-4

9. Peng CW, Yue WM, Poh SY, Yeo W, Tan SB. Clinical and radiological outcomes of minimally invasive versus open transforaminal lumbar interbody fusion. Spine (Phila Pa 1976). 2009;34(13):1385-1389. doi:10.1097/BRS.0b013e3181a4e3be

10. Kuslich SD, Ulstrom CL, Griffith SL, Ahern JW, Dowdle JD. The Bagby and Kuslich method of lumbar interbody fusion. History, techniques, and 2-year follow-up results of a United States prospective, multicenter trial. Spine (Phila Pa 1976). 1998;23(11):1267-1279. doi:10.1097/ 00007632-199806010-00019

11. Linson MA, Williams H. Anterior and combined anteroposterior fusion for lumbar disc pain. A preliminary study. Spine (Phila Pa 1976). 1991;16(2):143-145.

12. Ray CD. Threaded titanium cages for lumbar interbody fusions. Spine (Phila Pa 1976). 1997;22(6):667-680. doi:10. 1097/00007632-199703150-00019

13. Hanley EN Jr, David SM. Lumbar arthrodesis for the treatment of back pain. J Bone Joint Surg Am. 1999;81(5):716730. doi:10.2106/00004623-199905000-00015

14. Fritzell $P$, Hägg $O$, Wessberg $P$, Nordwall A, Swedish Lumbar Spine Study Group. 2001 Volvo Award Winner in Clinical Studies: Lumbar fusion versus nonsurgical treatment for chronic low back pain: a multicenter randomized controlled trial from the Swedish Lumbar Spine Study Group. Spine (Phila Pa 1976). 2001;26(23):2521-2534. doi:10.1097/ 00007632-200112010-00002

15. Lorenz $M$, Zindrick $M$, Schwaegler $P$, et al. A comparison of single-level fusions with and without hardware. Spine (Phila Pa 1976). 1991;16(8 Suppl):S455-S458. doi:10. 1097/00007632-199108001-00029

16. Zdeblick TA. A prospective, randomized study of lumbar fusion. Preliminary results. Spine (Phila Pa 1976). 1993;18(8):983-991. doi:10.1097/00007632-199306150-00006

17. Glazer PA, Colliou O, Lotz JC, Bradford DS. Biomechanical analysis of lumbosacral fixation. Spine (Phila
Pa 1976). 1996;21(10):1211-1222. doi:10.1097/00007632199605150-00015

18. Johnston C, Ashman R, Baird A, Allard R. Effect of spinal construct stiffness on early fusion mass incorporation experimental study. Spine (Phila Pa 1976). 1990;15(9):908-912. doi:10.1097/00007632-199009000-00013

19. Kornblatt MD, Casey MP, Jacobs RR. Internal fixation in lumbosacral spine fusion. A biomechanical and clinical study. Clin Orthop Relat Res. 1986;(203):141-150.

20. Gejo R, Matsui H, Kawaguchi Y, Ishihara H, Tsuji H. Serial changes in trunk muscle performance after posterior lumbar surgery. Spine (Phila Pa 1976). 1999;24(10):1023-1028. doi:10.1097/00007632-199905150-00017

21. Rantanen J, Hurme M, Falck B, et al. The lumbar multifidus muscle five years after surgery for a lumbar intervertebral disc herniation. Spine (Phila Pa 1976). 1993;18(5):568-574. doi:10.1097/00007632-199304000-00008

22. Clapham LM, Buckley J. Outcome-directed clinical practice in lumbar spine surgery. Clin Perform Qual Health Care. 1999;7(4):167-171. doi:10.1108/14664109910315587

23. Pull ter Gunne AF, Cohen DB. Incidence, prevalence, and analysis of risk factors for surgical site infection following adult spinal surgery. Spine (Phila Pa 1976). 2009;34(13):14221428. doi:10.1097/BRS.0b013e3181a03013

24. Deyo RA, Nachemson A, Mirza SK. Spinal-fusion surgery - the case for restraint. N Engl J Med. 2004;350(7):722726. doi:10.1056/NEJMsb031771

25. Lee MJ, Dettori JR, Standaert CJ, Ely CG, Chapman JR. Indication for spinal fusion and the risk of adjacent segment pathology: does reason for fusion affect risk? A systematic review. Spine (Phila Pa 1976). 2012;37(22 Suppl):S40-S51. doi:10.1097/BRS.0b013e31826ca9b1

26. Meyerding HW. Spondylolisthesis. Surg Gynecol Obstet 1932;54:371-377

27. Gallagher EJ, Liebman M, Bijur PE. Prospective validation of clinically important changes in pain severity measured on a visual analog scale. Ann Emerg Med. 2001;38(6):633-638. doi:10.1067/mem.2001.118863

28. Kelly AM. The minimum clinically significant difference in visual analogue scale pain score does not differ with severity of pain. Emerg Med J. 2001;18(3):205-207. doi:10.1136/emj.18. 3.205

29. Fairbank JC, Couper J, Davies JB, O’Brien JP. The Oswestry low back pain disability questionnaire. Physiotherapy. 1980;66(8):271-273.

30. Fairbank JC, Pynsent PB. The Oswestry disability index. Spine (Phila Pa 1976). 2000;25(22):2940-2952; discussion 2952. doi: 10.1097/00007632-200011150-00017.

31. Bridwell KH, Lenke LG, McEnery KW, Baldus C, Blanke K. Anterior fresh frozen structural allografts in the thoracic and lumbar spine. Do they work if combined with posterior fusion and instrumentation in adult patients with kyphosis or anterior column defects? Spine (Phila Pa 1976). 1995;20(12):1410-1418.

32. Goel VK, Lim TH, Gwon J, et al. Effects of rigidity of an internal fixation device. A comprehensive biomechanical investigation. Spine (Phila Pa 1976). 1991;16(3 Suppl):S155S161. doi:10.1097/00007632-199103001-00023

33. Slucky AV, Brodke DS, Bachus KN, Droge JA, Braun JT. Less invasive posterior fixation method following transforaminal lumbar interbody fusion: a biomechanical analysis. Spine J. 2006;6(1):78-85. doi:10.1016/j.spinee.2005.08.003 
34. Harris BM, Hilibrand AS, Savas PE, et al. Transforaminal lumbar interbody fusion: the effect of various instrumentation techniques on the flexibility of the lumbar spine. Spine (Phila Pa 1976). 2004;29(4):E65-E70. doi:10.1097/ 01.brs.0000113034.74567.86

35. Schleicher P, Beth P, Ottenbacher A, et al. Biomechanical evaluation of different asymmetrical posterior stabilization methods for minimally invasive transforaminal lumbar interbody fusion. J Neurosurg Spine. 2008;9(4):363-371. doi:10. 3171/SPI.2008.9.10.363

36. Yücesoy K, Yüksel KZ, Baek S, Sonntag VK, Crawford NR. Biomechanics of unilateral compared with bilateral lumbar pedicle screw fixation for stabilization of unilateral vertebral disease. J Neurosurg Spine. 2008;8(1):44-51. doi:10.3171/SPI$08 / 01 / 044$

37. Suk KS, Lee HM, Kim NH, Ha JW. Unilateral versus bilateral pedicle screw fixation in lumbar spinal fusion. Spine (Phila Pa 1976). 2000;25(14):1843-1847. doi:10.1097/00007632200007150-00017

38. Feng ZZ, Cao YW, Jiang C, Jiang XX. Short-term outcome of bilateral decompression via a unilateral paramedian approach for transforaminal lumbar interbody fusion with unilateral pedicle screw fixation. Orthopedics. 2011;34(5):364. doi:10.3928/01477447-20110317-05

39. Aoki Y, Yamagata M, Ikeda Y, et al. A prospective randomized controlled study comparing transforaminal lumbar interbody fusion techniques for degenerative spondylolisthesis: unilateral pedicle screw and 1 cage versus bilateral pedicle screws and 2 cages. J Neurosurg Spine. 2012;17(2):153-159. doi:10.3171/2012.5.SPINE111044

40. Xie Y, Ma H, Li H, et al. Comparative study of unilateral and bilateral pedicle screw fixation in posterior lumbar interbody fusion. Orthopedics. 2012;35(10):e1517e1523. doi:10.3928/01477447-20120919-22

41. Xue H, Tu Y, Cai M. Comparison of unilateral versus bilateral instrumented transforaminal lumbar interbody fusion in degenerative lumbar diseases. Spine J. 2012;12(3):209-215. doi:10.1016/j.spinee.2012.01.010

42. Dahdaleh NS, Nixon AT, Lawton CD, Wong AP, Smith ZA, Fessler RG. Outcome following unilateral versus bilateral instrumentation in patients undergoing minimally invasive transforaminal lumbar interbody fusion: a single-center randomized prospective study. Neurosurg Focus. 2013;35(2):E13. doi:10.3171/2013.5.FOCUS13171

43. Choi UY, Park JY, Kim KH, et al. Unilateral versus bilateral percutaneous pedicle screw fixation in minimally invasive transforaminal lumbar interbody fusion. Neurosurg Focus. 2013;35(2):E11. doi:10.3171/2013.2.FOCUS12398

44. Zhang K, Sun W, Zhao CQ, et al. Unilateral versus bilateral instrumented transforaminal lumbar interbody fusion in two-level degenerative lumbar disorders: a prospective randomised study. Int Orthop. 2014;38(1):111-116. doi:10. 1007/s00264-013-2026-y
45. Kabins MB, Weinstein JN, Spratt KF, et al. Isolated L4L5 fusions using the variable screw placement system: unilateral versus bilateral. J Spinal Disord. 1992;5(1):39-49. doi:10.1097/ 00002517-199203000-00006

46. Awad BI, Lubelski D, Shin JH, et al. Bilateral pedicle screw fixation versus unilateral pedicle and contralateral facet screws for minimally invasive transforaminal lumbar interbody fusion: clinical outcomes and cost analysis. Global Spine J. 2013;3(4):225-230. doi:10.1055/s-0033-1349399

47. Aoki Y, Yamagata M, Nakajima F, et al. Examining risk factors for posterior migration of fusion cages following transforaminal lumbar interbody fusion: a possible limitation of unilateral pedicle screw fixation. J Neurosurg Spine. 2010;13(3):381-387. doi:10.3171/2010.3.SPINE09590

48. Zhao FD, Yang W, Shan Z, et al. Cage migration after transforaminal lumbar interbody fusion and factors related to it. Orthop Surg. 2012;4(4):227-232. doi:10.1111/os.12004

49. Hu YH, Niu CC, Hsieh MK, Tsai TT, Chen WJ, Lai PL. Cage positioning as a risk factor for posterior cage migration following transforaminal lumbar interbody fusion - an analysis of 953 cases. BMC Musculoskelet Disord. 2019;20(1):260. doi:10.1186/s12891-019-2630-0

50. Kimura H, Shikata J, Odate S, Soeda T, Yamamura S. Risk factors for cage retropulsion after posterior lumbar interbody fusion: analysis of 1070 cases. Spine (Phila Pa 1976). 2012;37(13):1164-1169. doi:10.1097/BRS.0b013e318257f12a

51. Molinari RW, Saleh A, Molinari R Jr, Hermsmeyer J, Dettori JR. Unilateral versus bilateral instrumentation in spinal surgery: a systematic review. Global Spine J. 2015;5(3):185-194. doi:10.1055/s-0035-1552986

Disclosures and COI: No funds were received in support of this work. There are no potential conflicts of interest affecting the manuscript. Author Dr Sajan K. Hegde is a consultant to Globus Medicals and has intellectual property rights with royalties.

Corresponding Author: Keyur K. Akbari, Spine Unit, Apollo Hospitals, Greams Lane, Chennai 600006, India. Phone: +918980808179/ +919879137187; Email: keyur21088@yahoo.co.in.

Published 0 Month 2021

This manuscript is generously published free of charge by ISASS, the International Society for the Advancement of Spine Surgery. Copyright $\odot 2021$ ISASS. To see more or order reprints or permissions, see http://ijssurgery.com. 